\title{
Physico-chemical characterization and pharmacological evaluation of sulfated polysaccharides from three species of Mediterranean brown algae of the genus Cystoseira
}

Hiba Hadj Ammar ${ }^{1}$, Sirine Lajili ${ }^{2}$, Rafik Ben Said ${ }^{3}$, Didier Le Cerf ${ }^{4}$, Abderrahman Bouraoui $^{2}$ and Hatem Majdoub ${ }^{1 *}$

\begin{abstract}
Background: Seaweed polysaccharides are highly active natural substances having valuable applications. The present study was conducted to characterize the physico-chemical properties of sulphated polysaccharides from three Mediterranean brown seaweeds (Cystoseira sedoides, Cystoseira compressa and Cystoseira crinita) and to evaluate their anti-radical, anti-inflammatory and gastroprotective activities.

Methods: The different rates of neutral sugars, uronic acids, L-fucose and sulphate content were determined by colorimetric techniques. The different macromolecular characteristics of isolated fucoidans were identified by size exclusion chromatography equipped with a triple detection: multiangle light scattering, viscometer and differential refractive index detectors, (SEC/MALS/ND/DRI). Anti-inflammatory activity was evaluated, using the carrageenan-induced rat paw edema test in comparison to the references drugs Acetylsalicylate of Lysine and Diclofenac. The gastroprotective activity was determined using $\mathrm{HCl} / \mathrm{EtOH}$ induced gastric ulcers in rats and to examine the antioxidant effect of fucoidans in the three species, the free radical scavenging activity was determined using 1,1-diphenyl-2-picrylhydrazyl.

Results: The pharmacological evaluation of the isolated fucoidans for their anti-inflammatory, and their gastroprotective effect established that these products from C. sedoides, C. compressa and C. crinita exhibited a significant anti-inflammatory activity at a dose of $50 \mathrm{mg} / \mathrm{kg}$, i.p; the percentages of inhibition of the oedema were $51 \%, 57 \%$ and $58 \%$ respectively. And, at the same dose, these fucoidans from C. sedoides and C. compressa showed a significant decrease of the intensity of gastric mucosal damages compared to a control group by $68 \%$, whereas, the fucoidan from C. crinita produced a less gastroprotective effect. Furthermore, the isolated fucoidans exhibited a radical scavenging activity.
\end{abstract}

Conclusion: The comparative study of fucoidans isolated from three species of the genus Cystoseira showed that they have similar chemicals properties and relatives anti-radical, anti-inflammatory and gastroprotective activities which are found to be promising.

Keywords: Fucoidans, Cystoseiraceae, Cystoseira, SEC/MALS/NS/DRI, Anti-inflammatory activity, Gastroprotective activity

\footnotetext{
* Correspondence: hatemmajdoub2002@yahoo.fr

'Laboratoire des Interfaces et des Matériaux Avancés (LIMA), Faculté des

Sciences de Monastir, Université de Monastir, Bd. de l'environnement, 5019

Monastir, Tunisia

Full list of author information is available at the end of the article
} 


\section{Background}

Brown seaweeds represent a rich sources of several nutraceuticals components like laminarans, fucoidans, and polyphenols. Among these, fucoidans, a sulphated polysaccharide have been the subject of much interest in recent years, mainly due to their pharmacological and biological potential with anti-viral [1], anti-cancer [2], liver protection [3], anti-inflammatory [4] and antibacterial [5] properties and it also can affect the secretion of extracellular matrix proteins [6] and activate apoptosis [7]. Several studies have attempted to determine the exact structure of fucoidans but only a few examples of regularity in the structure were found. Links, ramifications, the position of the sulphates and other sugars appear to be variables [8]. Fucoidans are generally linear, mainly composed of repeated units of fucoses sulfated at C-2 and/or C-4 with a-(1-3) and/or a-(1-4) linkages [9]. They can also contain uronic acid, optionally acetylated and other neutral sugars such as D-galactose, D-xylose, D-glucose, D-mannose. However, this chemical composition varies depending on the algal specie and it can vary even within the same species. In this paper, we will focus on a comparative study of physicochemical and biological properties of fucoidans from three species of brown algae of the genus Cystoseira: C. sedoides, C. compressa and C. crinita. Our attention is particularly paid to this genus of algae for its abundance in the Mediterranean area and more specifically on the Tunisian coast sides. Furthermore, the only structural features of sulphated fucans from this genus of brown seaweed Cystoseira indica have been reported by (Mandal et al.) [10].

\section{Methods}

\section{Sample collection}

Brown seaweeds, (C. crinita, C. compressa, and C. sedoides) were harvested from the Mediterranean sea, from various areas of the coastal region of Monastir and Tabarka (Tunisia), in June 2007, at a depth between 1 and $3 \mathrm{~m}$. These brown algae are of the family of Cystoseiraceae. After collection, the seaweeds were rinsed with fresh water to remove associated debris and epiphytes. The cleaned material was then air dried in the shade at $30^{\circ} \mathrm{C}$. The dried samples were finally powdered and stored at $-20^{\circ} \mathrm{C}$ until use. Identification of specimens was carried out in the National Institute of Marine Sciences and Technologies (Salambôo, Tunisia).

\section{Extraction of crude polysaccharides}

The milled sample was soaked in Methanol-Dichloromethane (1:1) at room temperature for $48 \mathrm{~h}$ then filtered. This process was repeated three times. A sequential extraction of seaweed's powders was carried out with petroleum ether then acetone in a soxhlet apparatus to remove lipophilic pigments (such as chlorophylls) and low molecular weight proteins. Depigmented dried seaweeds were treated three times with $2 \%$ aqueous solution of $\mathrm{CaCl}_{2}$ during 3 hours, in order to precipitate alginates. After centrifugation, the supernatant enclosing the fucoidans was recovered and then purified by dialysis through tubing of molecular weight cut off $30 \mathrm{KDa}$ and then lyophilized.

\section{Chemical composition}

Total carbohydrates were determined for all the extracted polysaccharides by the phenol $-\mathrm{H}_{2} \mathrm{SO}_{4}$ method [11] using galactose as a standard. Whereas, uronic acids were determined using carbazole method [12] and glucuronic acid as a standard. The sulphate content of the polysaccharides was determined by the turbidimetric method using sodium sulphate $\left(\mathrm{Na}_{2} \mathrm{SO}_{4}\right)$ as a standard after hydrolyzing the polysaccharides in $2 \mathrm{M} \mathrm{HCl}$ at $100^{\circ} \mathrm{C}$ for $2 \mathrm{~h}$ [13]. The content of L-fucose units in fucoidans was estimated by a colorimetric assay with L-cysteine [14]. FTIR were performed in $\mathrm{KBr}$ pellets $(1 \mathrm{mg}$ polysaccharide in $100 \mathrm{mg} \mathrm{KBr}$ ). The spectra were recorded on a Perkin Elmer 1600 FTIR spectrometer from 400 to $4000 \mathrm{~cm}^{-1}$.

\section{Molecular weight determination}

Analysis of various samples was performed using size exclusion chromatography (SEC) equipped with a triple detection: multi-angle light scattering (MALS) (Down HELEOS II, Wyatt Technology, Ca, USA), viscometer detector (VD) (Viscostar II, Wyatt Technology, Ca, USA) and differential refractive index (DRI) (RID $10 \mathrm{~A}$ Shimadzu, Japan). The SEC system consists of a pump (LC10 Ai Shimadzu, Japan) at a flow rate $0.5 \mathrm{~mL} / \mathrm{min}$ and two columns OHPAK SB 804 and $806 \mathrm{HQ}$.

The samples were dissolved in the eluent $\left(\mathrm{LiNO}_{3}\right.$ $0.1 \mathrm{~mol} / \mathrm{L}$ ) at $2 \mathrm{~g} / \mathrm{L}$. The dissolution was carried out by stirring at $380 \mathrm{rpm}$ for $24 \mathrm{~h}$ at room temperature. $3 \mathrm{~mL}$ solutions were filtered through membrane 0.45 microns (regenerated cellulose) before injection.

The analyzes were performed by a data processing Zimm [15] "order 1" using angles from (from $34.8^{\circ}$ to $142.8^{\circ}$ ). The corresponding value of $\mathrm{dn} / \mathrm{dc}$, in our case is about $0.15 \mathrm{~mL} / \mathrm{g}$, the typical value for a polysaccharide [16]. The Astra 6.0.1.7 software package is set to collect and extrapolate data with the aim to obtain for each elution volume the molecular weight and the gyration radius. With an integration of the peak, we calculated the number $(\mathrm{Mn})$ and weight $(\mathrm{Mw})$ average molecular weight and the $\mathrm{z}$-average gyration radius.

The differential viscosimeter detector permits to obtain for each elution fraction the intrinsic viscosity. An integration of the peak gives the average intrinsic viscosity, which allowed us to obtain the average 
hydrodynamic volume (Vh) using the Einstein - Simha equation:

$$
\mathrm{Vh}=[\eta] \mathrm{M} / v \mathrm{~N}_{\mathrm{A}}
$$

where $\mathrm{N}_{\mathrm{A}}$ is Avogadro's number, $\mathrm{M}$ is the molar mass, $[\eta]$ is the intrinsic viscosity $\left(\mathrm{g} \mathrm{mL}^{-1}\right)$, and $v$ is a conformational parameter that takes the value of 2.5 in the case of a spherical conformation.

\section{DPPH (1,1-diphenyl-2-picrylhydrazyl) radical scavenging activity}

To examine the antioxidant effect of fucoidans in the three species, the free radical scavenging activity was determined using DPPH according to the method of Kim et al. [17]. A dilution series of the extracted samples was prepared $(0,0.25,0.5,0.75$ and $1 \mathrm{mg} / \mathrm{mL})$. A $1 \mathrm{~mL}$ volume of each sample was mixed with $1 \mathrm{ml}$ of $30 \mathrm{mmol} / \mathrm{L}$ DPPH-ethanol solution. The reaction mixture was then stirred vigorously for 10 seconds using the vortex. Color was allowed to develop in the dark for $30 \mathrm{~min}$. The absorbance is measured at $517 \mathrm{~nm}$ against the blank. Radical scavenging activity is expressed as the inhibition percentage and was calculated using the following formula:

$$
\begin{aligned}
& \text { Radical scavenging capacity }(\mathrm{RSC}, \%) \\
& \quad=1-\left[\left(\mathrm{A}_{\text {sample }}-\mathrm{A}_{\text {sample blank }}\right) / \mathrm{A}_{\text {control }}\right] \times 100 \text {. }
\end{aligned}
$$

Where the A control is the absorbance of the control (DPPH solution without sample), the $\mathrm{A}_{\text {sample }}$ is the absorbance of the test sample (DPPH solution plus test sample), and the $A_{\text {sample blank }}$ is the absorbance of the sample only (sample without DPPH solution).

\section{Pharmacological evaluation Animals}

All experiments were performed according to the guidelines established by the European Union on Animal Care (CCE Council 86/609). Wistar rats $(150-200 \mathrm{~g})$ of both sexes purchased from Pasteur Institute (Tunis, Tunisia) were used. They were housed in groups of eight to ten animals in plastic cages at $20-25^{\circ} \mathrm{C}$ and maintained on a standard pellet diet with free access to water. Animals were fasted for $24 \mathrm{~h}$ before the experiments.

\section{Anti-inflammatory activity}

The anti-inflammatory activity of isolated fucoidans was evaluated using the carrageenan induced rat paw oedema test. Wistar rats were divided into groups of six animals and the oedema was induced by injecting $0.05 \mathrm{ml}$ of $1 \%$ carrageenan subcutaneously into the subplantar region of the left hind paw [18]. Isolated fucoidans from C. crinita, C. sedoides and C. compressa (25 or $50 \mathrm{mg} / \mathrm{kg}$ ) and reference drugs were administered intraperitoneally (i.p.) $30 \mathrm{~min}$ before the injection of carrageenan. The control group received the vehicle (Saline water $2.5 \mathrm{ml} / \mathrm{kg}$, i.p.). The reference groups received Diclofenac (10 mg/kg, i.p) and (ASL, $300 \mathrm{mg} / \mathrm{Kg}$, i.p.).

Measurement of paw size was done by means of volume displacement technique using Plethysmometer (Ugo Basile no. 7140) immediately before carrageenan injection and 1, 2, 3, 4 and $5 \mathrm{~h}$ after carrageenan injection. Percentages of inhibition in our anti-inflammatory tests were obtained for each group using the following ratio:

$$
\left[(\mathrm{Vt}-\mathrm{Vo})_{\text {control }}-(\mathrm{Vt}-\mathrm{Vo})_{\text {treated }}\right] \times 100 /(\mathrm{Vt}-\mathrm{Vo})_{\text {control }}
$$

Where, Vt is the average volume for each group and Vo is the average volume obtained for each group before any treatment [19].

\section{Gastroprotective activity}

The gastroprotective activity of fucoidans from three species of genus Cystoseira was studied in $\mathrm{HCl} / \mathrm{EtOH}$ induced gastric ulcer [20]. Rats were divided into different groups, fasted for $24 \mathrm{~h}$ prior receiving an intraperitoneal injection of the isolated fucoidans (25 or $50 \mathrm{mg} / \mathrm{kg}$ ). Two other groups received Ranitidine $(60 \mathrm{mg} / \mathrm{kg}$, i.p.) and Omeprazole $(30 \mathrm{mg} / \mathrm{kg}$, i.p.) as reference drugs. After $30 \mathrm{~min}$, all groups were orally treated with $1 \mathrm{ml} / 100 \mathrm{~g}$ of $150 \mathrm{mM} \mathrm{HCl} / \mathrm{EtOH}(40: 60, \mathrm{v} / \mathrm{v})$ solution for gastric ulcer induction. Animals were sacrificed $1 \mathrm{~h}$ after the administration of ulcerogenic agent; their stomach were excised and opened along the great curvature, washed and stretched on cork plates. The surface was examined to detect the presence of lesions and to measure their extent. The summative length of the le-

\begin{tabular}{|c|c|c|c|c|c|c|}
\hline & & Yield* (\%) & Total sugar (\%) & Uronic acid (\%) & Sulfate $\left(\% \mathrm{SO}_{3} \mathrm{Na}\right)$ & Fucose (\%) \\
\hline \multirow[t]{3}{*}{ Fucoidans } & C. sedoides & 3.3 & 21.3 & 5.9 & 16.3 & 54.5 \\
\hline & C. compressa & 3.7 & 13.0 & 9.3 & 16.6 & 61.5 \\
\hline & C. crinita & 2.8 & 44.5 & 13.8 & 15.7 & 43.4 \\
\hline
\end{tabular}
sions along the stomach was recorded $(\mathrm{mm})$ as lesion index.

Table 1 Yields of extraction and carbohydrates analysis

*Yields of extraction given in \% of dry weight. 
Table 2 The most diagnostic peaks in the IR spectra of extracted polysaccharides

\begin{tabular}{llll}
\hline Fucoidans & & \multicolumn{2}{l}{ Assignment } \\
\cline { 1 - 2 } C. compressa & C. crinita & C. sedoides & \\
\hline $3421 \mathrm{~cm}^{-1}$ & $3411 \mathrm{~cm}^{-1}$ & $3412 \mathrm{~cm}^{-1}$ & O-H assoc. stretching vibration \\
$2925 \mathrm{~cm}^{-1}$ & $2925 \mathrm{~cm}^{-1}$ & $2928 \mathrm{~cm}^{-1}$ & C-H stretching vibration \\
$1652 \mathrm{~cm}^{-1}$ & $1641 \mathrm{~cm}^{-1}$ & $1639 \mathrm{~cm}^{-1}$ & C=O stretching vibration \\
$1457 \mathrm{~cm}^{-1}$ & $1441 \mathrm{~cm}^{-1}$ & $1423 \mathrm{~cm}^{-1}$ & $\begin{array}{l}\text { asymmetrical bending vibration } \\
\text { Of CH }\end{array}$ \\
$1263 \mathrm{~cm}^{-1}$ & $1231 \mathrm{~cm}^{-1}$ & $1231 \mathrm{~cm}^{-1}$ & S O stretching vibration \\
$1049 \mathrm{~cm}^{-1}$ & $1050 \mathrm{~cm}^{-1}$ & $1050 \mathrm{~cm}^{-1}$ & C-O-C stretching vibration \\
$826 \mathrm{~cm}^{-1}$ & $825 \mathrm{~cm}^{-1}$ & $825 \mathrm{~cm}^{-1}$ & C-O-S vibration \\
\hline
\end{tabular}

\section{Statistical analysis}

Results were analyzed using One Way ANOVA (Fisher LSD post hoc test) and expressed as mean \pm s.e.m, using SPSS Statistics Software (SPSS for Windows software release 18.0). Difference between means of treated and control groups were considered significant at $\mathrm{P}<0.05$.

\section{Results and discussion}

\section{Extraction and chemical analysis}

The main concern in the isolation procedures of fucoidans was to avoid their contamination with other polysaccharides, like laminaran and especially alginic acid. The hot extraction, in the presence of $\mathrm{CaCl}_{2}$ was allowed to separate the insoluble calcium alginate from the soluble fraction. This fraction is rich in fucoidan and laminaran. To eliminate this latter we had to recourse to dialysis.
The extraction yields show almost no difference between seaweed species (about 3\%) (Table 1). The yields obtained were in good agreement with Rioux et al. [9] for other seaweed species (Ascophyllum nodosum (3.3\%), Fucus versiculosus (4\%), Saccharina longicruris (2.6\%)).

The different colorimetric assays confirm that isolated polysaccharides are fucoidans, mainly composed by fucose (43 to 61\%). The amount of sulphates was determinated for the isolated fucoidans. There was no difference found between the three species; an average of $16 \%$ was observed for all. Besides, the isolated fucoidans were moderately sulphated compared to those of Cystoseira indica (11.5\%) [10], Saccharina longicruris (12\%) [9], Fucus vesiculosus (12\%) [21] and Sargassum stenophyllum (28\%) [22].

The FTIR spectrums of the isolated polysaccharides show typical absorption bands of fucoidan. Their exact absorption peaks are given in (Table 2). The intensity of the bands at $3400-3200 \mathrm{~cm}^{-1}$ was assigned to the deformation of $\mathrm{O}-\mathrm{H}$. The bands between 3000 and $2925 \mathrm{~cm}^{-1}$ were attributed to the $\mathrm{C}-\mathrm{H}$ stretching frequency and the strong absorption at approximately $1050 \mathrm{~cm}^{-1}$ corresponded to the $\mathrm{C}-\mathrm{O}-\mathrm{C}$ stretching frequency of the glycosidic bonds [23]. Besides, the extracted fractions showed all absorption at 1650-1620 $\mathrm{cm}^{-1}$, indicating the presence of uronic acid. The characteristic absorption bands of fucoidan are those who indicate the presence of sulphate $\left(\mathrm{SO}_{4}\right)$ and methyl $\left(\mathrm{CH}_{3}\right)$ groups, as fucoidan contains mainly fucose [24], which is a monosaccharide that has a methyl group attached to the C5 position. The signals at $1457-1423 \mathrm{~cm}^{-1}$ were attributed to the asymmetrical bending vibration of

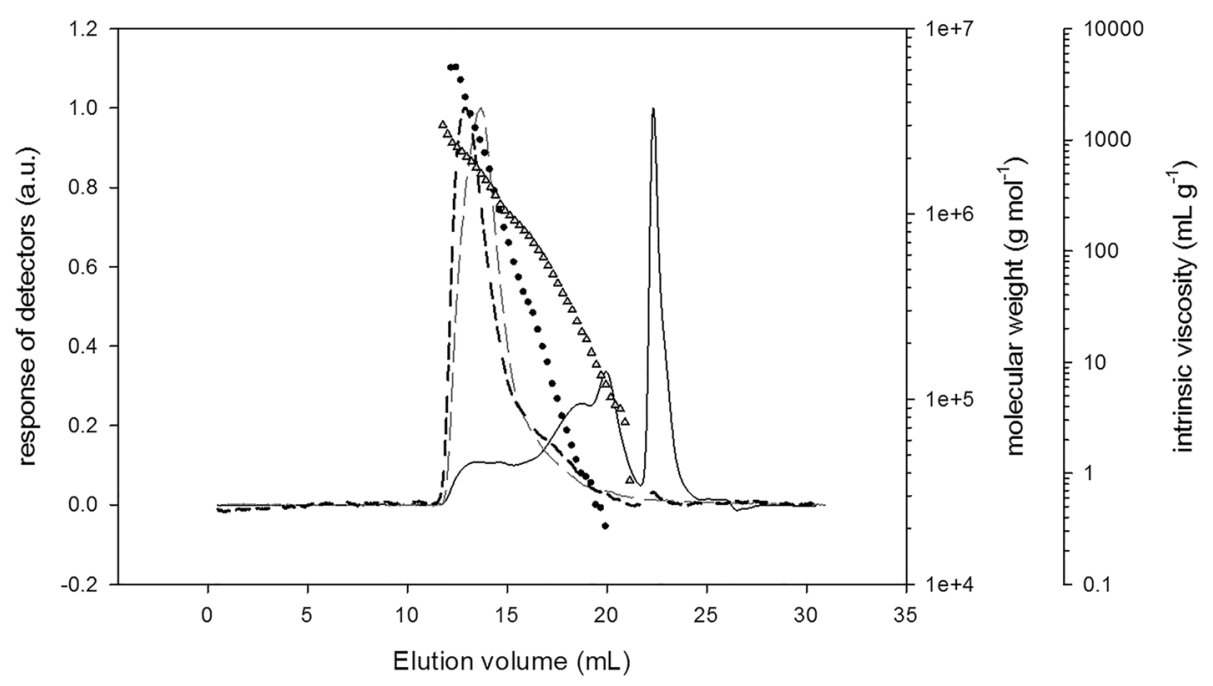

Figure 1 Elution profiles of $C$. sedoides sample with $\mathrm{Mw}$ and $[\eta]$ distribution determined by SEC/MALS/VS/DRI in $0.1 \mathrm{~mol} \mathrm{~L}^{-1} \mathrm{LiNO}_{3}$ aqueous solution. Differential refractive index (full line), light scattering at $90^{\circ}$ (dotted black line), specific viscosity (dotted grey line), Mw: molecular weight (black circles) and [n] intrinsic viscosity (grey triangle). 


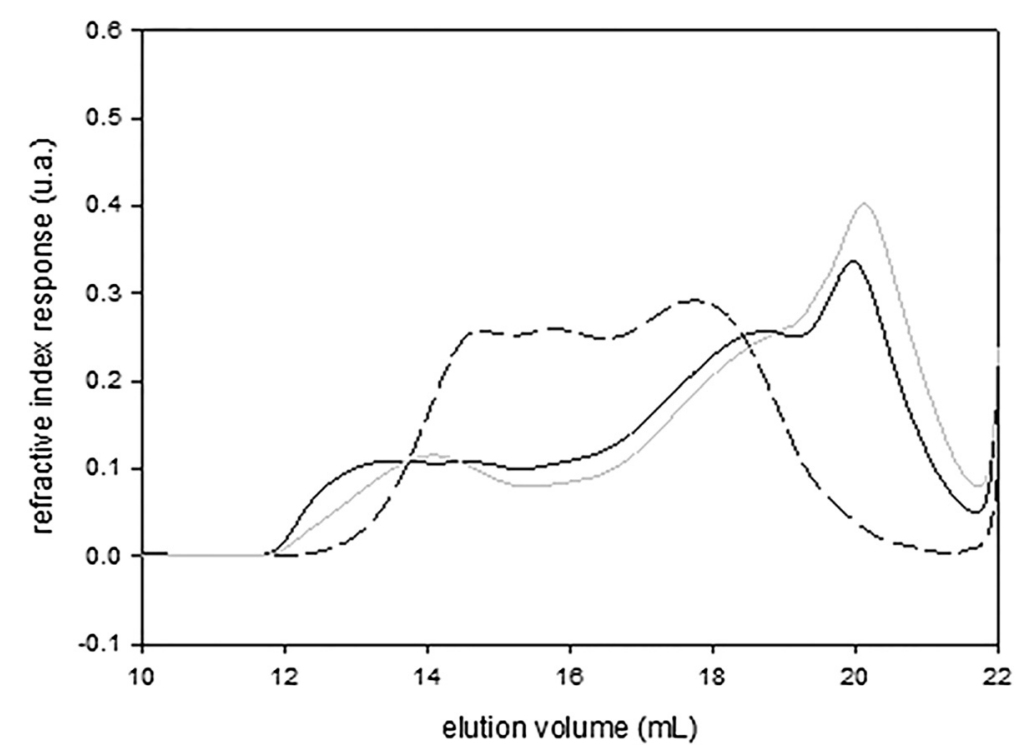

Figure 2 Elution profiles from differential refractive index of different extract determined by SEC/MALS/VS/DRI in $0.1 \mathrm{~mol} \mathrm{~L}^{-1} \mathrm{LiNO}_{3}$ aqueous solution. C. sedoides (full black line), C. compressa (dotted black line) and C. crinita (full grey line).

$\mathrm{CH}_{3}$. The strong absorption band at $1255-1240 \mathrm{~cm}^{-1}$ ( $\mathrm{S}=\mathrm{O}$ stretching) confirms the presence of a significant amount of sulfate in the polysaccharides. The sharp band at $820 \mathrm{~cm}^{-1}$ (C-S-O) suggest that the majority of sulphate groups occupy positions 2 and/or 3 (equatorial positions) [25].

SEC/MALS/VD/DRI experiments were carried out in $0.1 \mathrm{~mol} / \mathrm{L} \mathrm{LiNO}_{3}$ to determine molecular weights and size information of biopolymers studied. As an example, we have reported on (Figure 1) the elution profiles and the molecular weight and intrinsic viscosity distribution of $C$. sedoides sample. The Polysaccharides are eluted between 11 and $22 \mathrm{~mL}$ showing a large distribution. After $22 \mathrm{~mL}$ the peak obtained with refractive index detector is due to donnan effect on salt. Firstly, between 11 and $16 \mathrm{~mL}$, light scattering and viscometric responses are intensive with a relative low concentration response (DRI). Consequently, C. sedoides have very long macromolecular chains with molecular weight up the 1000 000 g. $\mathrm{mol}^{-1}$. An other population is eluted from $16 \mathrm{~mL}$ to $22 \mathrm{~mL}$. The DRI exhibits high intensity with low intensity for MALS and DV detectors. The molecular weights are lower and it is no possible to obtain gyration radii due to isotropic diffusion. Nevertheless, we can estimate hydrodynamic radii all along the elution volume with viscometric data. In conclusion, SEC/MALS/VD/DRI analysis permits to obtain some characteristics of whole sample as Mn, Mw, polydispersity index (Đ) weight average $(\mathrm{Rh})$ and $[\eta]$.

Same analysis was made on the two other fucoidan samples. We have reported only the refractive index response for a better view of the three samples (Figure 2). C. sedoides and C. crinita are separated in the same way. They have similar molecular repartition. C. compressa has a shorter distribution of molecular weight with a peak between 13 and $20 \mathrm{~mL}$. All results are summarized in (Table 3). The presence of very short chain in the two samples $C$. sedoides and C. crinita decreases drastically the $\mathrm{Mn}$ and consequently increases the polydispersity. In the same way, very high molecular weights obtained at the beginning of the peak (between 12 and $13 \mathrm{~mL}$ ) influence greatly the intrinsic viscosity and

Table 3 Average macromolecular characteristics of fucoidans isolated from C. crinita, C. compressa, and C. sedoides) determined by SEC/MALS/VD/DRI (0.1 $\left.\mathrm{mol} / \mathrm{L} \mathrm{LiNO}_{3}\right)$

\begin{tabular}{llllllll}
\hline & & $\mathbf{M n}(\mathbf{g} / \mathbf{m o l})$ & $\mathbf{M w}(\mathbf{g} / \mathbf{m o l})$ & $\mathbf{\Xi}^{*}$ & {$[\mathbf{n}]\left(\mathbf{m L} \cdot \mathbf{g}^{-\mathbf{1}}\right)$} & $\mathbf{R}_{\mathbf{H}}(\mathbf{n m})$ & $\mathbf{a}^{\mathbf{*}}$ \\
\hline Fucoidans & C. sedoides & 26000 & 642000 & 24 & 133 & 18 & 0.73 \\
& C. compressa & 114000 & 545000 & 4.8 & 92 & 14 & 0.70 \\
& C. crinita & 18000 & 339000 & 18.2 & 125 & 18 & 0.84 \\
\hline
\end{tabular}

${ }^{*} \bigoplus=\mathrm{Mw} / \mathrm{Mn}$, polydispersity index.

**a: the Mark Houwink exponent. 
Table 4 EC50 values of fucoidans extracted from C. crinita, C. compressa, and $C$. sedoides in radical scavenging activity

\begin{tabular}{lllll}
\hline & Ascorbic acid & C. sedoides & C. compressa & C. crinita \\
\hline $\mathrm{EC50*}(\mathrm{mg} / \mathrm{ml})$ & $0.13 \pm 0.01$ & $0.96 \pm 0.01$ & $0.84 \pm 0.06$ & $0.76 \pm 0.04$ \\
\hline
\end{tabular}

*EC50 value: the effective concentration at which the antioxidant activity was $50 \%$; the absorbance was 0.5 for reducing power; 1,1-diphenyl-2-picrylhydrazyl (DPPH).

average hydrodynamic diameter, which are obtained by weight average.

The knowledge of molecular weight and intrinsic viscosity for each elution volume can be used to determine the Mark-Houwink exponent. Values between 0.7-0.8 are in agreement with random coil conformation [26].

However, it's important to note that chemical composition, molecular weight and structure varies depending on the source of fucoidans, the harvest period and the extraction methods.

\section{DPPH radical scavenging activity}

$\mathrm{DPPH}$ is a stable radical that can directly react with anti-oxidants. It has been used extensively as a free radical to evaluate reducing substances and is a useful reagent for investigating the free radical scavenging. When the DPPH radical is scavenged by anti-oxidants through the donation of hydrogen to form a stable DPPH-H molecule, the color changes from purple to yellow. In this work, DPPH free-radical scavenging effect of each sample was calculated and the $\mathrm{EC}_{50}$ values were presented in (Table 4). Fucoidans from different species (C. crinita, C. compressa and C. sedoides) exhibited DPPH radical scavenging activity with an EC50 value of $0.76 \mathrm{mg} / \mathrm{mL}$, $0.84 \mathrm{mg} / \mathrm{mL}$ and $0.96 \mathrm{mg} / \mathrm{mL}$, respectively. These scavenging effects of fucoidans, were less important than produced by the reference compound, Ascorbic acid and decreased in this order C. crinita $>$ C. compressa $>C$. sedoides.

\section{Anti-inflammatory activity}

Carrageenan has been widely used as a noxious agent to induce experimental inflammation for the screening of compounds possessing anti-inflammatory activity. This phlogistic agent, when injected locally into the rat paw, induced a severe inflammatory reaction, discernible within $30 \mathrm{~min}$ [27]. Administration of fucoidans of C. sedoides, C. crinita and C. compressa (25 and $50 \mathrm{mg} / \mathrm{kg}$, i.p.) produced a significant reduction of oedema throughout the period of observation in a dose-related manner. The experimental results are shown in (Table 5). All the isolated fucoidans showed significant anti-inflammatory activity; in fact treatment with sulphated polysaccharides from C. sedoides, C. compressa and C. crinita (at the dose of $50 \mathrm{mg} / \mathrm{kg}$, i.p.) inhibited the formation of the oedema by $51 \%, 56.81 \%$ and $58.21 \%$, respectively, $3 \mathrm{~h}$ after the administration of carrageenan. Results were statistically significant compared to the control and are quite similar to those observed for both the group treated with Diclofenac $(10 \mathrm{mg} / \mathrm{kg}$ ) and ASL (acetylsalicylic of lysine $300 \mathrm{mg} / \mathrm{kg}$ ) which inhibited oedema formation by $55.07 \%$ and $56.81 \%$, respectively. Carrageenan induced inflammation in a biphasic phenomenon [28]. The first phase of oedema is attributed to release of histamine and 5-hydroxytryptamine and the second accelerating phase of swelling is attributed to prostaglandin like substances. The knowledge of these mediators involved in different phases is important for interpreting the mode of fucoidan action. Fucoidans might have inhibited the release or actions of the various chemical mediators such as histamine, 5-HT, kinins,

Table 5 Effect of the administration of fucoïdanes isolated from C. sedoides, C. compressa and C. crinita and reference drugs in carrageenan induced rat paw edema

\begin{tabular}{|c|c|c|c|c|c|c|c|c|}
\hline \multirow{2}{*}{\multicolumn{2}{|c|}{ Samples }} & \multirow[t]{2}{*}{ Dose $(\mathrm{mg} / \mathrm{kg})$} & \multicolumn{3}{|c|}{ Edema $\left(\mathrm{mL} \times 10^{-2}\right)$} & \multicolumn{3}{|c|}{ Edema inhibition $(\%)^{*}$} \\
\hline & & & $1 \mathrm{~h}$ & $3 \mathrm{~h}$ & $5 \mathrm{~h}$ & $1 \mathrm{~h}$ & $3 \mathrm{~h}$ & $5 \mathrm{~h}$ \\
\hline \multicolumn{2}{|l|}{ Control } & - & $26 \pm 2.75$ & $57.5 \pm 1.51$ & $59 \pm 3.27$ & - & - & - \\
\hline \multicolumn{2}{|c|}{ ASL (reference) } & 300 & $17.66 \pm 1.63$ & $24.83 \pm 1.72$ & $29.33 \pm 1.21$ & 32.07 & 56.81 & 50.28 \\
\hline \multicolumn{2}{|c|}{ Diclofenac (reference) } & 10 & $15.66 \pm 5.12$ & $25.83 \pm 2.40$ & $28.66 \pm 3.61$ & 39.76 & 55.07 & 51.42 \\
\hline \multirow[t]{6}{*}{ Fucoidans } & C. sedoides & 25 & $13.66 \pm 3.20^{* * *}$ & $29.66 \pm 5.20^{* * *}$ & $40.16 \pm 4.70^{* * *}$ & $47.46^{\mathrm{a}}$ & $48.41^{a}$ & $31.93^{\mathrm{a}}$ \\
\hline & & 50 & $10.66 \pm 4.08^{* * *}$ & $28.16 \pm 3.38^{* * *}$ & $41.66 \pm 1.21^{* * *}$ & $59.00^{b}$ & $51.02^{a}$ & $29.38^{a}$ \\
\hline & C. compressa & 25 & $12.66 \pm 2.73^{* * *}$ & $26.83 \pm 1.04^{* * *}$ & $29.83 \pm 2.40^{* * *}$ & $51.30^{a}$ & $53.33^{a}$ & $49.44^{a}$ \\
\hline & & 50 & $11.83 \pm 4.09^{* * *}$ & $24.83 \pm 2.48^{* * *}$ & $28.00 \pm 2.36^{* * *}$ & $54.50^{a}$ & $56.81^{a}$ & $52.54^{a}$ \\
\hline & C. crinita & 25 & $12.66 \pm 3.43^{* * *}$ & $26.50 \pm 3.39 * * *$ & $19.83 \pm 1.94^{* * *}$ & $51.28^{a}$ & $54.17^{\mathrm{a}}$ & $66.38^{a}$ \\
\hline & & 50 & $13.20 \pm 2.68^{* * *}$ & $24.16 \pm 2.56^{* * *}$ & $28.50 \pm 2.50^{* * *}$ & $49.23^{a}$ & $58.21^{\mathrm{a}}$ & $51.69^{b}$ \\
\hline
\end{tabular}

Data are expressed as mean \pm s.e.m. $(n=6)$.

${ }^{*}$ Mean values with different superscript letters in the same row are significantly different at $\mathrm{p} \leq 0.05$.

*** $p<0.001$. 
and prostanoids known to mediate acute inflammation induced by phlogistic agents.

\section{Gastroprotective activity}

The results of gastroprotective activity of the isolated compounds from C. compressa, C. sedoides and C. crinita on gastric ulcer induced by $\mathrm{HCl} /$ ethanol solution are shown in (Table 6). Oral administration of the damaging agent to the control group clearly produced a mucosal damage characterized by multiple hemorrhage red bands of different sizes along the long axis of the glandular stomach. Pretreatment with fucoidans of C. compressa, C. sedoides and C. crinita (25, $50 \mathrm{mg} / \mathrm{kg}$, i.p.) produced significant decrease in the intensity of gastric mucosal damages induced by the necrotizing agent $\mathrm{HCl}$ / $\mathrm{EtOH}$ compared with control group. Fucoidans from C. compressa and C. sedoides at the dose of $50 \mathrm{mg} / \mathrm{kg}$ produced an important protective effect against gastric mucosal lesion which is quite similar to the effect produced by the reference drug, ranitidine. The percentage of inhibition of ulcer were $68.18 \%, 68.51 \%$ respectively for fucoidans from C. compressa and C. sedoides. However, fucoidan from $C$. crinita showed less protection (59.90\% of inhibition).

$\mathrm{HCl}$-ethanol induced gastric mucosal lesions may be multifactorial, with static blood flow contributing significantly to the hemorrhagic as well as the necrotic aspects of the tissue injury [29]. The decrease in the number of lesions may be due the reduction in the levels of gastric secretion [30]. The alteration in the acidity/volume of the gastric juice is due to the production of $\mathrm{HCl}$, which may increase the permeability of the mucosal membrane [31]. Thus, the overall protection by fucoidans against $\mathrm{HCl}$-ethanol induced gastric ulceration in experimental

\begin{tabular}{|c|c|c|c|}
\hline Samples & $\begin{array}{l}\text { Dose } \\
(\mathrm{mg} / \mathrm{kg})\end{array}$ & $\begin{array}{l}\text { Average lesion } \\
(\mathrm{mm})\end{array}$ & $\begin{array}{l}\text { Ulcer inhibition } \\
(\%)^{*}\end{array}$ \\
\hline Control & - & $50.33 \pm 5.50$ & - \\
\hline Ranitidine (reference) & 60 & $43.38 \pm 4.35$ & 66.96 \\
\hline Oméprazole (reference) & 30 & $17.50 \pm 1.38$ & 86.67 \\
\hline \multirow[t]{2}{*}{ Fucoidans } & 25 & $20.83 \pm 2.56^{* * *}$ & $58.57 \pm 5.09^{a}$ \\
\hline & 50 & $16.00 \pm 2.19^{* * *}$ & $68.19 \pm 4.35^{b}$ \\
\hline \multirow[t]{2}{*}{ C. sedoides } & 25 & $22.83 \pm 3.70^{* * *}$ & $54.60 \pm 7.37^{\mathrm{a}}$ \\
\hline & 50 & $15.83 \pm 4.60^{* * *}$ & $68.51 \pm 5.24^{b}$ \\
\hline \multirow[t]{2}{*}{ C. crinita } & 25 & $28.33 \pm 4.09^{* * *}$ & $43.66 \pm 5.13^{a}$ \\
\hline & 50 & $20.17 \pm 6.17^{* * *}$ & $59.90 \pm 7.26^{b}$ \\
\hline
\end{tabular}

Data are expressed as mean \pm s.e.m. $(n=6)$.

* Mean values with different superscript letters in the same row are significantly different at $\mathrm{p} \leq 0.05$.

*** $p<0.001$. rats suggest that it contains some anti-ulcer agents that may hasten the decomposition of free radicals generated, thereby strengthening the gastric mucosal antioxidant defense system suggesting an gastroprotective effect of fucoidans from brown algae.

\section{Conclusion}

The comparative study of fucoidans isolated from three species of the genus Cystoseira showed that they have similar properties regarding the percentage in sulphates, L-fucose content and their molecular weight. However this requires an advanced structural study to determine the length of the general chain and the branching of fucoidans.

These similarities are reflected on pharmacological activities; in fact the different isolated fucoidans have similar anti-radical, anti-inflammatory and gastroprotective activities which are found to be promising.

\section{Abbreviations}

ASL: Acetylsalicylic of lysine; C. sedoides: Cystoseira sedoides;

C. compressa: Cystoseira compressa; C. crinita: Cystoseira crinita; Mn: Average molecular number; Mw: Average molecular weight; Rh: Average

hydrodynamic diameter; [n]: Intrinsic viscosity; Đ: Polydispersity index.

\section{Competing interests}

The authors declare that they have no competing interests.

\section{Authors' contributions}

$H M$ and $A B$ were the supervisors and designed the study. HA contributes to the extraction of fucoidan from three brown algae and to the chemical study. SL carried out pharmacological activities. DL made contribution to the discussion of SEC/MALSND/DRI results. Identification of specimens was carried by RS. All authors read and approved the final manuscript.

\section{Acknowledgements}

We gratefully acknowledge the financial support of the Doctorale School of Materials, Devices and Microsystems of Monastir, further special thanks goes to Mr. Christophe Rihouey for the technical support regarding SEC/MALS/ VD/DRI analyses.

\section{Author details}

'Laboratoire des Interfaces et des Matériaux Avancés (LIMA), Faculté des Sciences de Monastir, Université de Monastir, Bd. de l'environnement, 5019 Monastir, Tunisia. ${ }^{2}$ Laboratoire de développement chimique, galénique et pharmacologique des médicaments, Faculté de Pharmacie de Monastir, Université de Monastir, 5000 Monastir, Tunisia. ${ }^{3}$ Institut National des Sciences et Techniques de la Mer (INSTM), Salambôo, Tunis, Tunisia. ${ }^{4}$ Université de la Normandie, Laboratoire Polymères Biopolymères Surfaces, UMR 6270 CNRS Université de Rouen, FRE 3101 CNRS, 76821 Mont Saint Aignan, France.

Received: 1 October 2014 Accepted: 3 January 2015

Published online: 13 January 2015

\section{References}

1. Hayashi K, Nakano T, Hashimoto M, Kanekiyo K, Hayashi T. Defensive effects of a fucoidan from brown alga Undaria pinnatifida against herpes simplex virus infection. Int J Immunopharmacol. 2008:8:109-16.

2. Liu JM, Bignon J, Haroun-Bouhedja F, Bittoun P, Vassy J, Fermandjian S. Inhibitory effect of fucoidan on the adhesion of adenocarcinoma cells to fibronectin. Anticancer Res. 2005;25:2129-33.

3. Saito A, Yoneda M, Yokohama S, Okada M, Haneda M, Nakamura K. Fucoidan prevents concanavalin A-induced liver injury through induction of endogenous IL-10 in mice. Hepatol Res. 2006;35:190-8. 
4. Maruyamaa H, Tamauchib H, Hashimotoc M, Nakano T. Suppression of Th2 immune responses by Mekabu fucoidan from Undaria pinnatifidaSporophylls. Int Arch Allergy Immunol. 2005;137:289-94.

5. Zapopozhets TS, Besednova NN, Loenko IN. Antibacterial and immunomodulating activity of fucoidan. AntibiotKhimioter. 1995;40:9-13.

6. Moon HJ, Park KS, Ku MJ. Effect of Costaria costata Fucoidan on expression of matrix metalloproteinase-1 promoter, mRNA, and protein. J Nat Prod. 2002;72:1731-4.

7. Senthilkumar K, Manivasagan P, Venkatesan J, Kim SK. Brown seaweeds fucoidan: biological activity and apoptosis, growth signaling mechanism in cancer. Int J Biol. 2013;60:366-74.

8. Ponce NMA, Pujol CA, Damonte EB, Flores ML, Stortz CA. Fucoidans from the brown seaweed Adenocystis utricularis: extraction methods, antiviral activity and structural studies. Carbohydr Res. 2003;338:153-65.

9. Rioux LE, Turgeon SL, Beaulieu M. Characterization of polysaccharides extracted from brown seaweeds. Carbohyd Polym. 2007;69:530-7.

10. Mandal P, Mateu CG, Chattopadhyay K, Pujol CA, Damonte EB, Ray B. Structural features and antiviral activity of sulphated fucans from the brown seaweed Cystoseira indica. Antivir Chem Chemother. 2007;18:153-62.

11. Dubois M, Gilles KA, Hamilton JK, Rebers PA, Smith F. Colorometric method for determination for sugars and related substances. Anal Chem. 1956;28:350-6.

12. Bitter T, Muir HM. A modified carbazole method for uronic acid determination. Anal Biochem. 1962;4:330-4.

13. Dodgson KS, Price RG. A note on the determination of the ester sulphate content of sulphated polysaccharides. Biochem J. 1962:84:106-10.

14. Dische Z, Shettles LB. A specific color reaction of methyl pentoses and a spectrophotometric micromethod for their determination. Biol Chem. 1948;175:595-603.

15. Zimm BH. The scattering of light and the radial distribution function of high polymer solutions. J Chem Phys. 1948;16:1093-8.

16. Majdoub H, Roudesli S, Deratani A. Polysaccharides from prickly pear peel and nopals of Opuntia ficus-indica: extraction, characterization and polyelectrolyte behavior. Polym Int. 2001;50:552-60.

17. Kim JK, Noh JH, Lee S, Choi JS, Suh H, Chung HY. The first total synthesis of 2, 3, 6-tribromo-4, 5- dihydroxybenzyl methyl ether (TDB) and its antioxidant activity. Korean ChemSoc. 2002;23:661-2.

18. Winter CA, Risley EA, Nuss GW. Carrageenin-induced edema in hind paw of the rat as assay for anti-inflammatory drug. Proc Soc Exp Biol. 1962;111:544-7.

19. Lanhers MC, Fleurentin J, Dorfman P, Moitrier F, Pelt JM. Analgesic, antipyretic and Anti-inflammatory properties of Euphorbia hirta. Planta Med. 1991:57:225-31.

20. Hara N, Okabe S. Effect of gefernate on acute lesions in rats. Folia Pharmacol Jpn. 1985;85:443-8.

21. Rupérez P, Ahrazem O, Lea JA. Potential antioxidant capacity of sulfated polysaccharides from the edible marine brown seaweed Fucus vesiculosus. J Agric Food Chem. 2002;50:840-5.

22. Duarte ME, Cardoso MA, Noseda MD, Cerezo AS. Structural studies on fucoidans from the brown seaweed Sargassum stenophyllum. Carbohydr Res. 2001;333:281-93.

23. Wang Q, Song Y, He Y, Ren D, Kow F, Qiao Z, et al. Structural characterisation of algae Costaria costata fucoidan and its effects on CCl4-induced liver injury. CarbohydrPolym. 2014;107:247-54.

24. Ale MT, Maruyama H, Tamauchi $H$, Mikkelsen JD, Meyer AS. Fucoidan from Sargassum sp. and Fucus vesiculosus reduces cell viability of lung carcinoma and melanoma cells in vitro and activates natural killer cells in mice in vivo. Int J Biol. 2011;49:331-6.

25. Qiu X, Amarasekara A, Doctor V. Effect of oversulfation on the chemical and biological properties of fucoidan. CarbohydrPolym. 2006;63:224-8.

26. Villay A, Lakkisdefillipis F, Picton L, Lecerf D, Vial C, Michaud P. Comparison of polysaccharide degradations by dynamic High Pressure Homogenisation. Food Hydrocolloids. 2012;27:278-86.

27. Borgi W, Ghedira K, Chouchane N. An antiinflammatory and analgesic activity of Zizyphus lotus roots barks. Fitoterapia. 2007;78:16-9.

28. Vinegar R, Schreiber W, Hugo RJ. Biphasic development of carrageenin edema in rats. J Pharmacol Exp Ther. 1969:166:96-103.
29. Guth PH, Paulsen G, Nagata H. Histologic and microcirculatory changes in alcohol-induced gastric lesions in the rat: effect of prostaglandin cytoprotection. Gastroenterol. 1984;87:1083-90

30. Wormsley K. Progress report the pathophysiology of duodenal ulceration. G Gut. 1974;15:59-64.

31. Dayton MT, Kauffman GL, Schlegel JF. Gastric bicarbonate appearance with ethanol ingestion. Mechanism and significance. Dig Dis Sci. 1983;28:449-55.

\section{Submit your next manuscript to BioMed Central and take full advantage of:}

- Convenient online submission

- Thorough peer review

- No space constraints or color figure charges

- Immediate publication on acceptance

- Inclusion in PubMed, CAS, Scopus and Google Scholar

- Research which is freely available for redistribution 